\title{
The Degree of Mastery of Female Science Teachers of the Main Objectives of Science in the Light of the Constructive Theory Characteristics
}

\author{
Waleed Nawafleh ${ }^{1, *}$, Shamm'a Bani Amer ${ }^{2}$ \\ ${ }^{1}$ Department of Curriculum and Instruction, Faculty of Education, Yarmouk University, Irbid, Jordan \\ ${ }^{2}$ Ministry of Education, Irbid, Jordan
}

Received December 15, 2020; Revised February 1, 2021; Accepted February 24, 2021

\section{Cite This Paper in the following Citation Styles}

(a): [1] Waleed Nawafleh, Shamm'a Bani Amer, "The Degree of Mastery of Female Science Teachers of the Main Objectives of Science in the Light of the Constructive Theory Characteristics," Universal Journal of Educational Research, Vol. 9, No. 3, pp. 512-527, 2021. DOI: 10.13189/ujer.2021.090311.

(b): Waleed Nawafleh, Shamm'a Bani Amer (2021). From Ladle to Chalk and Pencil: Parents in the New Normal of Philippine Education System. Universal Journal of Educational Research, 9(3), 512-527. DOI: 10.13189/ujer.2021.090311.

Copyright $\mathrm{C} 2021$ by authors, all rights reserved. Authors agree that this article remains permanently open access under the terms of the Creative Commons Attribution License 4.0 International License

\begin{abstract}
This study aimed to reveal the degree of mastery of female science teachers of the main objectives of science in the light of the constructive theory characteristics and to reveal the differences between the arithmetic averages of the degree of mastery according to the variables: qualification, teaching experience, and constructive characteristics. To achieve the objectives of the study, the researchers used the descriptive method. The sample of the study consisted of (81) female science teachers from public schools in the Directorate of Education in the Northern Al-Mazar and Bani Ubaid, who was chosen randomly. The test of the main objectives of science was applied to the science teachers after confirming its validity and reliability, and the constructive theory characteristics scale was also applied after ensuring its validity and reliability on (405) female students of grades (9-12) who were purposely chosen to evaluate their teachers and to reveal the extent of their possession of the characteristics of the constructivist theory. The results of the study indicated that the mastery of science level among female teachers of the main objectives of science was moderate and that just one of the main objectives of science came with a high level which is "Control", and the other three objectives were moderate "description, Interpretation, prediction". The results also showed that the level of possessing constructive characteristics among female science teachers was moderate. The study found a statistically significant difference at $(\alpha=0.05)$ attributed to
\end{abstract}

the constructive characteristics in the level of science teachers' mastery of science in favor of the female teachers who possess constructive characteristics, while there were no statistically significant differences at $(\alpha=0.05)$ attributed to qualification and teaching experience.

Keywords Science Objectives, Constructive Theory Characteristics, Female Science Teachers, the Degree of Mastery

\section{Introduction}

At the beginning of the $20^{\text {th }}$ century, the educational process has witnessed several changes in the education system in line with the development of theories related to it and based on the philosophical schools which existed back then. This is clear in the educational system of the Arab world to reach the quality in education and try to strengthen the educational process in its different aspects which include students, teachers, and curricula accompanied by the knowledge explosion and the scientific and technical development.

Several educational efforts that targeted at the learning and education field called for going beyond the frame of the behavioral theory which focuses on the cognitive 
structure and adopting the modern theories in education, including the constructivism learning theory that transcended the limits of indoctrination in education, which focused on the teacher (his personality, enthusiasm, and reinforcement), the school, and the curriculum, to a new approach that is based on the idea that students actively construct their knowledge through their previous knowledge, wrong concepts, motivation to learn, and thinking patterns [1].

The constructive theory stood out in recent years as a dominant model in education that has a great intellectual impact on the development of pedagogy, especially math and science [2]. This theory has offered a comprehensive perspective to teach science and to learn in the class to improve the effectiveness of science education in enhancing student teaching [3]. The success of constructivism theory may be due to the frustration learners experienced with behavioral educational practices [4], to move from "false or superficial learning" to what is known as "meaningful learning", or the true learning orientation [5].

In the context of educational reforms, the emphasis was placed on science teachers and their understanding of science, the facts, theories, and phenomena as they are responsible for the transmission of this understanding to students, and the emphasis was also placed on building and developing students' knowledge in line with the principles of constructive learning [6]. Besides, it stressed that the science teachers must have enough knowledge that qualifies them to deal with all the scientific events, phenomena, and problems they face to teach science adequately, and forming an integrated mentality and personality of the learner and raise a generation of scientists to achieve progress and happiness [7]. These reforms had an impact on the teaching philosophy, curriculum content, teaching methods, teachers' training, and characteristics and methods of evaluating learning and teaching [8].

The science concept is considered one of the concepts which had won great interest among scientists in terms of defining it and selecting its elements and objectives [9]. As a result, there are a lot of definitions for the term "science". For example, Bhattacherjee [10] defines it as the craft of the scientists who use specialized tools in labs to reach knowledge. Al-Najdi, Rashid and Abdul-Hadi [11] define it as an individual or cooperative human activity that aims to study, explain, and predict the different natural and universal phenomena to reach the facts, the laws, and the theories which might rule these phenomena for the good of the main kind. As for the American Association for the Advancement of Science [AAAS] in [12], it has defined science as the process of producing knowledge that depends on making accurate observations of the phenomena and creating theories to understand these observations.

Science aims to understand the world around us and use it to serve humanity through scientific systems that do not stop at the superficial understanding of the phenomena but go on to analyze the phenomena [9]. After the researchers examine the educational literature, they found that there is a disagreement between educators in defining the science objectives, but there are four common objectives in the educational literature. The first objective is "description", which means describing the different natural and universal phenomena based on the accuracy of the observation and using the scientific devices and tools [11]. However, we cannot know the real world through observation only because it might mislead us [13], therefore; we should not be satisfied with observing and describing the phenomena no matter how the description is accurate because it does not lead to understanding the phenomena or knowing how it accrued and that is why we need an explanation [14].

The second objective is the explanation, which means recognizing the causes of the phenomena or the circumstances of its occurrence. This process needs an awareness of the relationships and to which extent the different phenomena that need to be explained are connected, and between the events that accompany or proceed them [15]. Thus, the purpose of the explanation is for the students to understand how the world works by relating the causes and effects of the natural phenomena by asking why and how [16].

The third objective is prediction, which depends on description and explanation using the obtained information from scientific principles, and rules in predicting new future phenomena. Predictions depend on the information validity, if the information is valid and true then we will obtain scientifically true or acceptable predictions. Their validity can be verified through mental conclusions and scientific experiments. And if the validity of the predictions is not proven to be correct, the information must be reviewed in the light of the new results. Accordingly, the prediction has a rule in the science development [17], and through it can benefit from the phenomena or avoid its occurrence or reduce its damages [18].

The fourth objective is "control" which means that the more the person can describe, explain, and predict phenomena, the more the person will be able to control the factors which lead to the occurrence of the phenomena, prevent, or predict them under certain circumstances, and conditions [19].

Science has different characteristics, in which the first one is subjectivity, which means that researchers should look at the research material without bias and excluding the personal experience, and not being influenced by human desires and tendencies. The dispute arising between the researchers can be resolved by experiment which is considered the test of correctness in scientific research, where researchers reach the same conclusion when studying any phenomenon [15]. The second one is inclusiveness, which means that the researcher studies a small sample to find out the general characteristics of the whole group which is consistent with the rest of the group. 
These characteristics enable the researcher to obtain a general rule, accordingly; extract a law that applies to the whole group. This helps the researcher to predict specific events [20]. The third one is relativeness, which means that the results of the researchers are not absolute and subject to change. Thus, certainty is not possible in educational research as well as in natural science [19].

The fourth one is constructive-cumulative, which means that the scientist does not start from the starting point but completes what others have accomplished so far. Moreover, the scientist who studies the natural phenomena uses the objectives of science to reach new scientific results, which in its turn motivates him to research and investigate the natural phenomena [21]. The fifth one is a global human activity; it means that science is a human production that is crystallized by scientific thinking and research. Also, it does not belong to anyone, as any person or group can use the scientific terminologies, principles, and theories and apply them no matter who they belong to or who discovers them. Consequently, when scientific knowledge appears it becomes everyone's property and goes beyond geographic or political borders [17]. The sixth one is accuracy and abstraction, which means that researchers depend in their study on accurate information by confirming its accuracy of the information, and sometimes they might resort to repetition to confirming its accuracy [22]. Besides, the researcher seeks to determine the research problem first, then the methodology objectively and accuracy using abstract language and signs to control the reality and understand its laws. It depends on accurate scientific measures to list the facts which support their point of view so that the result will be consistent with reality [23].

To achieve the intended goal of education, the educational reforms have turned into the constructive theory, as a theory of learning, which is a reaction to the traditional teaching or more broadly on cognitive knowledge. And when it's viewed as a learning theory it focuses on the question "how do learners acquire knowledge?" it is students centered as an active learner although most cognitive viewpoints that are related to learning agree with the active learners' concept. However, constructive focus more on learners building their understanding [24]. Therefore, science education requires providing students with an educational environment that enhances their understanding, through their participation in activities, as the interaction of learners with each other helps build their understanding and develop their appropriate skills to solve problems to achieve meaningful learning [3].

Constructivist theory is characterized by some characteristics, some of them which include: to focus on what is going on inside the students' minds from previous experiences, to give them the appropriate opportunities to build new knowledge by encouraging them to search, investigate and use higher mental procedures. Also, to focus on the students' independence in learning and taking responsibility for their education, to encourage them to present and accept initiatives, to urge them to share what they have learned among themselves and employ it while doing a task or in a life situation [25].

Suhendi and Purwarno in [26] and Juvova et al in [27] indicated several principles of the constructive theory; the first one was the effective construction of meaning, implying that the meaning was built effectively by the learner himself with a focus on the learners' activity. It also organized their experiences into cognitive structures known as mental schemas which are consistent with individual mental development. This new knowledge depended on the previous knowledge and experience. The second principle was the role of social influences on constructive, which referred to the role of others in the learning process through cooperative, social, real, and meaningful groups. The third principle was the availability of different tools that helped the learner to communicate effectively through language as it was one of the most important tools of communication. Thus, linguistic awareness was important in the constructive theory. In addition to the importance of the self-directed actions towards the learners to increase their motivation for learning, another principle was to focus on problem-solving using the appropriate methodology in the grew phase which achieved further learning. And finally, implementing teaching methods that suited the different types of intelligence, personality, and learning methods.

Zaiton and Zaiton in [1] stressed the effective role of the teacher in providing the constructive learning environment and making the constructive theory applicable, considering that the teacher is one of the important aspects in the education process. As for Fernando and Marikar in [28], considered the teacher as an academically qualified person and have knowledge that is specialized to the topic being taught, and that his role in teaching is not limited to transferring knowledge only, but he must make the learning process an active one where the student is an active participant inconsistent with the constructive approach.

Among the constructive teacher's principles is that they listen to their students, allow them to talk about their previous experiences, provide them with feedback, ask questions with appropriate time to answer, supervise their students' education, guides and facilitate it for them, allow them to participate in the evaluation which encourages students to be independent, leaders and adopt with the educational process which reinforces the important relationships between the student and the teacher [29]. Also, they provide tangible support and visual aids such as models, choose the appropriate activities for students which they are familiar with to facilitate learning the more complicated ideas, give their students the chance to classify and gather the information according to its complexity then use the outlines and hierarchies to facilitate linking the new information with the previous ones. Also, the constructive teacher poses problems to 
students that need logical analytical thinking and predicting future results, thus enhancing the important levels of interaction between students and teacher as well [30].

Based on the foregoing, the importance of the teacher's role in the educational process emerges, as it is necessary to train them well through a program that includes three major fields: specialized scientific training, professional training, and cultural training. As for the specialized scientific training includes the scientific material which science teacher should teach to reach a high level of specialized ability [31]. Whereas, the professional training includes courses about science teaching methods in line with learning theories including constructive theory. And through cultural training, the science teacher should teach scientific materials to reflect science as a material and a method that emphasizes the science's main objectives (description, explanation, prediction, and control) [32].

The teaching process does not involve transferring the knowledge only, but it is more than that. The constructive learning theory calls for a participatory approach for students to participate actively in the learning process and focus on learners emphasizing their way of learning more than the teacher and the identified amount of memorization [33]. As for the teacher's role, it is represented in facilitating the learning process and activate the teaching practices associated with it as well [28].

By reviewing the previous literature review, some studies linked to the current research were found. These studies aimed to reveal the degree to which science teachers employ the principles of constructivism theory in their teachings such as in the study of Barakat [3] which indicated that science teachers often employ the principles of constructivism theory while teaching, and there are no differences in the degree to which they employ the principles of constructivism theory due to the variables of gender, experience, and scientific qualification of the teacher.

And some aimed to reveal the impact of knowledge of constructivist theory and its principles on teaching practices such as the Shumba study [35] which aimed to identify the extent to which teachers knowledge of constructive learning principles affects both: teaching science and students learning, teachers and students role while teaching and learning science and the sequencing in the process of learning science, The results showed that the level of teachers' knowledge of constructive theory was low and that most of the sample members confirmed that the pre-educational concepts represent the foundation in which building knowledge in the mind of the learners is based on.

While Awad study [36] aimed to identify the extent of science teacher's knowledge of constructive theory, the extent of practice teaching based on it, and its impact on the student's achievement, the results showed that the teachers' knowledge of constructive theory is average, their teaching practice based on the theory is also average and there are statistically significant differences between the average achievement of students who were taught by teachers with low knowledge and teachers with high knowledge of constructive theory which is in favor of the later. Also, there is a statically significant difference between the average achievement of students who were taught by teachers with low knowledge and teachers with high knowledge of constructive theory which is in favor of the teachers with high knowledge of constructive theory.

Besides, Habib [37] pointed out that the level of teachers' practice of constructive teaching was large, and there are statistically significant differences in the field of "interest in providing effective scientific activities" related to gender variable in favor of females. Also, the results showed that there are no significant differences in the level of teachers practicing constructive teaching related to the educational qualification, experience, and the operating system.

On the one hand, Tura [38] conducted a study in Jordan that aimed to investigate the extent of science teachers implementing the constructive theory principles. The results showed that the extent of science teachers implementing the constructive theory principles was high, and there are no statically significant differences in the level of science teachers implementing the constructive theory principles related to gender, where there are statically significant differences in the level of implementing related to the educational qualification in favor of graduate studies, while the experience variable in favor of having an experience. Some studies dealt with understanding the nature of science and its effect on teaching practices.

Madi [32] in his study, aimed to identify the level of science teachers' understanding of the nature of science and its philosophy in the light of some variables. The results showed that the percentage of teachers who understand the nature of science and its philosophy is high in the science objectives field, followed by the science characteristics field, science assumptions, and history of scientific knowledge field. Then, the results of the science, scientists' behaviors, and finally science philosophy field with the low percentage. The results also showed that there are no differences between science teachers understanding of science nature and its philosophy that is related to gender, teachers' level of study, experience, and specialty while there is significant difference related to (scientists' behaviors) and (science assumptions) between physics, biology and general science teachers that are in favor of physics teachers. Additionally, there are differences related to course variable that is in favor of the teachers who studied courses related to science nature and its philosophy, moreover; there are differences related to academic qualification variable that is in favor of the teachers with a higher qualification than bachelor's degree. 
Furthermore, Aslan and Tasar in [39] aimed to investigate the nature of science for science teachers and its reflection on their educational practices in Anatolia (Turkey). The data were collected using a questionnaire, semi-organized interviews, and classroom note cards. The results showed that the teachers have traditional perspectives on multiple dimensions of the nature of science and that their opinions were not directly reflected in their classroom practices.

It is clear from the previous studies which have been presented that they agree with the current study by using the same study sample, the methodology used is descriptive, and they all have used a questionnaire as a tool to collect data. Oppositely, they differed from the current study in terms of its aim. Most of these studies have focused on some aspects of the constructive theory in terms of the extent of knowledge and use the constructive learning principles and practice them, as stated in the studies $[34,35,36,37,38]$. Additionally, some of the studies related to the nature of science discussed teachers' understanding and belief about the nature of science such as Madi's study [32], while some other studies discussed teachers understanding of science nature and constructive teachings such as Aslan and Tasar [39].

As for the current study, it aims to know the female teachers' mastery degree of the science objectives considering their possession of constructive theory characteristics, and that what differentiates it from the previous studies. It is also distinguished from the previous studies by writing an essay test which aims to know the female science teacher's mastery degree of the science objectives, which can be used by educational supervisors to help them direct the science teachers' practices in the classroom environment. Also, the study results can give a full perspective of those in charge of teachers training in the Jordanian universities to emphasize the science objectives and the characteristics of the constructive theory.

Since teachers are important and the necessity to train them well for their big role in the success of the educational process and their role in achieving the science objectives, by enhancing the students' efforts in building the scientific knowledge and invest it in constructive fields and help them understand the world around them. And since the studies which discussed the main science objectives are rare - within the researchers' knowledge-, this study was conducted to find out the female science teachers mastery degree of the main science objectives in the light of some Variable, through answering the following questions:

- To what degree do female science teachers possess the characteristics of constructivist theory in the schools of Bani-Ubaid province and the northern Mazar province from their student's point of view?

- What is the degree of mastery of science teachers to the main science objectives in the schools of
Bani-Ubaid province and the northern Mazar province?

- Is there a difference between female science teachers' mastery of the main objectives of science attributed to differences in the educational qualification and years of experience?

- Is there a difference between female science teachers' mastery of the main objectives of science attributed to the difference in possessing the characteristics of the constructive theory from their students' point of view?

\subsection{Procedural Definitions}

Mastery degree of science objectives: Procedurally, it is defined as the extent to which female science teachers in the study sample know the main science objectives (description, explanation, prediction, and control), which is measured by the degree the teacher gets in her performance in a test that consists of (12) scientific phenomena and events in the field of physics, chemistry, biology, and earth science, which are reflected using a high, moderate, or a low degree.

Constructive theory characteristics: Procedurally, it is defined as the degree to which the science teacher gets from the average of five evaluations of female students, who the teacher teaches on the items of the prepared tool for the study purpose. It includes several items related to the constructive theory characteristics which the science teacher should be committed to and consider to be constructive while teaching.

Female science teachers: Teachers who teach science material from $9^{\text {th }}$ to $12^{\text {th }}$ grade which include different specialty (chemistry, physics, biology, earth science, and science teacher) in the first semester of the academic year 2019/2020, in the study sample schools.

Educational Qualification: The educational qualification after bachelor's degree (higher diploma, master, and Ph.D.).

\subsection{Study Limits}

The study is limited to the female science teachers who teach science for grade nine and above, in two directorates of education in Irbid governorate, namely: the northern Mazar province and Bani-Ubaid province, in the first semester of the academic year 2019/2020. Also, the study is limited to the extent of the seriousness of female teachers and students who are evaluating their teachers in answering the study tool items, and the extent of validity and reliability of the study tools.

\section{Methodology}

This study used the descriptive approach which describes the actual reality of the female science teachers' 
degree of mastery of the main objectives of science in the light of the constructive characteristics by using the two tools: the first is a scale of the characteristics of the constructive theory, and the second represents a test of the main science objectives.

\subsection{Study Population and Sample}

The study population consisted of (121) female science teachers, divided into two groups; the first includes all the female science teachers who are teaching science courses from nine grade to twelve grade in the schools of the directorate of education of northern Mazar province and Bani-Ubaid province. The second group includes all the students from nine grade to twelve grade from the same schools for the first semester of the academic year 2019/2020. A random sample of female teachers (81) was selected from the teacher population, distributed on the study variables (academic qualification and years of experience). And the second group included a sample of (405) students who are taught by the selected female science teachers, by five students for every teacher who are selected using the purposeful method among the high achieving students assuming that they are the most capable to understand the questionnaire content and though can evaluate their teachers.

\subsection{Study Tools}

\subsubsection{The First Tool: Constructive Theory Characteristics Scale}

This scale was developed after reviewing the tools used in previous studies that dealt with constructive theory and constructivist learning, including studies of Barakat [34] and Awad [36]. Initially, a scale with (44) statements was used and examined through a five Likert scale, where (5) is very high (4) is high (3) is medium, (2) and (1) is very low, to measure the extent to which science teachers possess the characteristics of constructive theory from the viewpoint of their students.

\subsubsection{Content Validity of the Scale}

To ensure the content validity of the scale, the tool was presented to a group of specialized arbitrators in science curricula, measurement, and evaluation. Considering their suggestions and recommendations, some statements were modified, and two statements were deleted. Thus, the scale ended up with (42) statements (appendix .1).

\subsubsection{Construct validity of the Scale}

The validity of the scale construction was verified by calculating the corrected correlation coefficient for the correlation of each statement of the overall scale. All the values of the corrected correlation coefficients were greater than $(0.20)$, as they ranged between $(0.20)$ and (0.55), and all of them were acceptable for achieving the purposes of the current study [40].

\subsubsection{Reliability of the Scale}

To verify the reliability of the scale, an exploratory sample of (53) female students from the ninth and tenth grades selected to evaluate two female teachers. And the scale was applied to them and re-applied on the same sample after two weeks. A correlation coefficient between them was calculated using the Pearson formula, and it was (0.89). The internal consistency coefficient of the scale was calculated using the Cronbach Alpha and its value was (0.93). As both results are high, confirming the reliability of the test.

\subsubsection{The Statistical Standard}

To determine whether the teachers possess the characteristics of constructive theory (obtained) constructive ), (not obtained (traditional)); The ratio (70\%) was used as a cutoff, which corresponds to arithmetic mean (3.5) out of (5), and the teacher who attain (3.5) and more she possesses the characteristics of constructive theory.

\subsubsection{The Second Tool: Main Science Objectives Understanding Test}

The test was built after reviewing science textbooks and observing some scientific phenomena and events. The test consisted of (48) essay questions distributed on (12) scientific phenomena and events in physics, chemistry, biology, and geoscience. Each phenomenon consisted of four questions, with a question for each of the science objectives: description, interpretation, prediction, and control. As shown in Appendix (2).

\subsubsection{The Validity of the Test}

To ensure the content validity of the test, the tool was presented to a group of specialized arbitrators in science curricula, measurement and evaluation, and science school supervisors. Their suggestions and recommendations were limited to paraphrasing some statements to be more cohesive and scientific.

\subsubsection{Reliability of the Test}

To verify the reliability of the test, it was applied to an exploratory sample of (18) science teachers from the study population and outside of its sample. After two weeks, the same sample was retested, and the repetition reliability coefficient was calculated using the Pearson formula for each of its dimensions and the overall test. The values of the reliability coefficients for the dimensions ranged between (0.83) and (0.91) and the overall test was (0.88). These values are considered acceptable for the study as indicated in [40].

\subsubsection{Test Correction}

The test was corrected according to model answers that were determined by university professors and educational 
supervisors specializing in every scientific field of the phenomenon. Two marks were given if the answer was complete, one mark if the answer was incomplete, zero for the wrong answer. The maximum score for each goal was (24), and for the overall test (96). To determine a degree that enables science teachers to achieve the main science objectives a statistical standard was used based on the arithmetic average on all test items after converting it from (100). Some specialists in science curricula were consulted, and it was agreed on the following scale (less than $60 \%$ : low, $60 \%-80 \%$ : medium, $80 \%-100 \%$ : high).

\subsection{Procedures}

To achieve the study objectives, the following figure was followed:

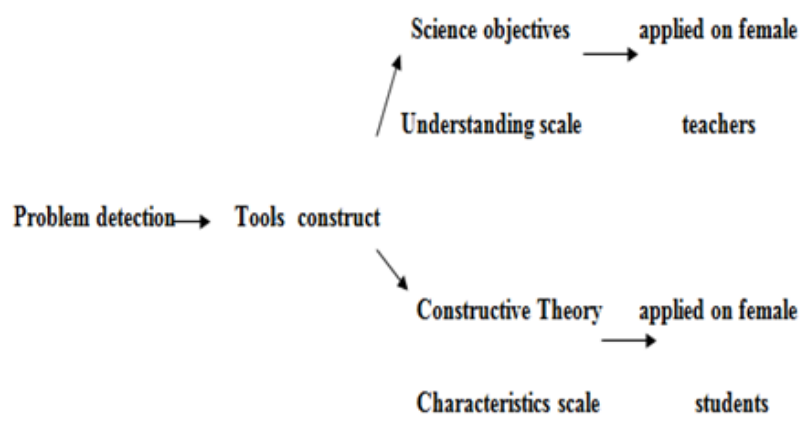

Figure 1. Study Procedures

\subsection{Study Variables}

A. Independent variables, which include:

- Educational qualification: it includes two categories (with qualification, without a qualification).

- Years of experience: it has three levels (less than 5 years, 5- less than 10 years, and 10 or more).

- The teachers possessing the constructive theory characteristics: it includes two categories (does not possess constructive characteristics (traditional), possess constructive characteristics (constructive)).

B. The dependent variable includes the following:

- The science teachers possessing the characteristics of all the constructive theory.

- The science teachers' mastery of science main objectives.

\section{Results}

\subsection{Results of the First Question}

The question states: "To what degree do female science teachers possess the characteristics of constructivist theory in the schools of Bani-Ubaid province and the northern
Mazar province from the students' point of view?" To answer this question, means and the standard deviation of the participants" estimates "the students" were calculated on the items of the study tool regarding the female science teachers possessing all the constructive characteristics, which value reached (3.74) with a percentage of (74.8\%), indicating that female science teachers' possession of the constructive characteristics is moderate. Besides, the study sample (teachers) was classified according to their possession of the constructive characteristics from their students' point of view into two categories (does not possess constructive characteristics (traditional), possess constructive characteristics (constructive), according to the statistical norm, where the frequencies and the percentages were calculated for every category as shown in Table (1).

Table 1. Frequencies and percentages of the two categories of constructive theory characteristics possessed by the study respondents

\begin{tabular}{|l|c|c|}
\hline $\begin{array}{l}\text { constructive characteristics } \\
\text { categories }\end{array}$ & Frequencies & Percentages \% \\
\hline $\begin{array}{l}\text { Does not possess constructive } \\
\text { characteristics (traditional) }\end{array}$ & 28 & 34.6 \\
\hline $\begin{array}{l}\text { possess constructive } \\
\text { characteristics (constructive) }\end{array}$ & 53 & 65.4 \\
\hline Total & 81 & 100.0 \\
\hline
\end{tabular}

Table (1) shows that (65.4\%) of the teachers possess the characteristics of the constructive theory with the frequency of (53) teachers out of (81) teacher, and that $(34.6 \%)$ of them do not possess constructive characteristics with the frequency of (28) teacher out of (81) teacher.

\subsection{Results of the Second Question}

The question states: "What is the degree of mastery of female science teachers to the main science objectives in the schools of Bani-Ubaid province and the northern Mazar province?" To answer this question, means and the standard deviations of the respondents' estimate were calculated for every objective of the objectives of science (description, explanation, prediction, and control) and upon them all together, see table (2).

Table 2. Means and the standard deviations of the respondents' estimate for every objective of the main objectives of science

\begin{tabular}{|c|c|c|c|c|c|}
\hline $\begin{array}{c}\text { Science main } \\
\text { objectives }\end{array}$ & Means & SD & Percent & Rank & Degree \\
\hline Control & 22.67 & 2.33 & 94.46 & 1 & High \\
\hline Description & 18.54 & 3.76 & 77.25 & 2 & moderate \\
\hline Explanation & 17.67 & 3.61 & 73.63 & 3 & moderate \\
\hline Prediction & 15.25 & 3.62 & 63.54 & 4 & moderate \\
\hline $\begin{array}{c}\text { Science main } \\
\text { objectives } \\
\text { combined }\end{array}$ & 74.13 & 9.26 & 77.22 & moderate \\
\hline
\end{tabular}

* The highest score for every goal is 24 .

** the highest score of the total test is 96 . 
Table (2) shows that the female science teachers' mastery of all the main objectives of science is (moderate) with a mean (74.13), standard deviation (9.26), and percentage (77.22\%). The science objective (control) came in the first place with a high degree, followed by (description) in the second place with a moderate degree, then (explanation) in the third place with a moderate degree, and finally (prediction) in the last place with a Medium degree.

\subsection{Results of the Third Question}

The question states: "Is there a difference among female science teachers' mastery of the main objectives of science attributed to differences in the educational qualification and years of experience?" To answer this question, means and the standard deviations of the participants' estimates were calculated for the overall test items of the objectives of science, which are related to the female science teacher's mastery of the science main objectives according to the variables (educational qualification and years of experience), see table (3).

Table 3. Means and the standard deviations of respondents' estimates for the overall test items of the main objectives of science according to the variables (educational qualification and years of experience)

\begin{tabular}{|c|c|c|c|c|c|c|}
\hline \multirow{2}{*}{$\begin{array}{c}\text { Years of } \\
\text { experience }\end{array}$} & \multicolumn{4}{|c|}{ Educational qualification } & \multicolumn{2}{c|}{ Total } \\
\cline { 2 - 7 } & \multicolumn{2}{|c|}{ With } & \multicolumn{2}{c|}{ Without } & & \\
\cline { 2 - 7 } & Means & SD & Means & SD & Means & SD \\
\hline Less than 5 Years & 73.35 & 8.99 & 72.00 & 14.88 & 73.13 & 9.97 \\
\hline 5- 10 years & 74.85 & 10.69 & 78.14 & 4.78 & 76.00 & 9.06 \\
\hline 10 years and more & 73.70 & 8.29 & 74.25 & 16.28 & 73.76 & 9.12 \\
\hline Total & 73.82 & 8.88 & 75.47 & 11.02 & 74.12 & 9.26 \\
\hline
\end{tabular}

Table (3) shows apparent differences between the means of the female science teachers' estimates for the overall test items of the main objectives of science objectives attributed to variables (educational qualification and years of experience). And to identify the statistical significance of these apparent differences, the two-way ANOVA was implemented. See table (4).

Table 4. The two-way ANOVA of the means of the female science teachers' estimates for the test items for mastery of the science main objectives according to the variables (educational qualification and years of experience)

\begin{tabular}{|c|c|c|c|c|c|}
\hline Variable & SS & DF & MS & F-value & Sig \\
\hline $\begin{array}{c}\text { Educational } \\
\text { qualification }\end{array}$ & 7.810 & 1 & 7.810 & 0.087 & 0.768 \\
\hline $\begin{array}{c}\text { Years of } \\
\text { experience }\end{array}$ & 120.332 & 2 & 60.166 & 0.673 & 0.513 \\
\hline $\begin{array}{c}\text { Educational } \\
\text { qualification } \\
\text { xyears of } \\
\text { experience }\end{array}$ & 43.030 & 2 & 21.515 & 0.241 & 0.787 \\
\hline Error & 6700.819 & 75 & 89.344 & & \\
\hline Adjusted total & 6856.765 & 80 & & & \\
\hline
\end{tabular}

Table (4) shows that the value of the statistical significance of the educational qualification variable is (0.768), which is higher than the level of the statistical significance at $(\alpha=0.05)$. This indicates that there is no statistical significance difference between two means of the study sample estimates on the overall test items attributable to the educational qualification variable. Also, Table (4) shows that the value of the statistical significance for the years of experience is (0.513), which is more than the level of the statistical significance at $(\alpha=0.05)$, indicating that there are no statistically significant differences between the means of the respondents' estimate for the all-test items attributed to the years of experience variable.

Table (4) also shows that the value of the statistical significance according to the correlation between the variable of the educational qualification and years of experience reached (0.787), which is more than the level of the statistical significance at $(\alpha=005)$. This indicates that are no statistically significant differences between the means of the respondents' estimates for all the test items, attributed to the correlation between the variable of the educational qualification and years of experience.

\subsection{Results of the Fourth Question}

The question states: "Is there a difference between female science teachers' mastery of the main objectives of science main attributed to the difference in possessing the characteristics of the constructive theory from their students' point of view?" To answer this question, means and the standard deviation of the study sample were calculated on all the test items according to the variable (possessing constructive characteristics), see table (5).

Table 5. Means and the standard deviations of the study sample performance for the total test items of the science main objectives according to the variable (possessing constructive characteristics)

\begin{tabular}{|c|c|c|}
\hline Possess constructive characteristics & Means & SD \\
\hline Does not possess (traditional) & 67.54 & 9.62 \\
\hline Possess (constructive) & 77.60 & 6.93 \\
\hline
\end{tabular}

* The highest score for the total test $=96$ 
Table (5) shows an apparent difference between the two means of the study sample performance on all the test items attributed to the variable of "possessing constructive characteristics). And to determine the statistical significance of this apparent difference, the (T-test) was implemented to the two independent groups, see Table (6).

Table 6. T-test results of two independent groups of the two means of the study sample performance on the total test items according to the variable (possessing constructive characteristics)

\begin{tabular}{|c|c|c|c|c|c|}
\hline $\begin{array}{c}\text { Possess constructive } \\
\text { characteristics }\end{array}$ & Mean & SD & T-value & DF & Sig \\
\hline Does not possess (traditional) & 67.54 & 9.62 & \multirow{2}{*}{$*-5.417$} & 79 & 0.000 \\
\hline Possess (constructive) & 77.60 & 6.93 & & \\
\hline
\end{tabular}

* A statistically significant difference at the level $(\alpha=0.05)$

Table (6) shows that the value of $(\mathrm{T}=-5.417)$ of the variable (possess constructive characteristics) with a statistical significance of (0.000), which is less than the statistical significance level at $(\alpha=0.05)$. This indicates that there is a statistically significant difference between the two means of the study sample performance on the overall test items of science objectives, attributed to the variable (possessing constructive characteristics), and in favor of the teachers who possess constructive characteristics. The means and the standard deviations of the study sample performance were also calculated on every main objective of science according to the variable (possessing constructive characteristics), see table (7).

Table 7. Means and standard deviations of responses on every main objective of science according to the variable (possessing constructive characteristics)

\begin{tabular}{|c|c|c|c|c|c|c|}
\hline \multicolumn{4}{|c|}{ possessing constructive characteristics } & \multicolumn{3}{c|}{ Total } \\
\hline $\begin{array}{c}\text { The main } \\
\text { Dojectives of science }\end{array}$ & Means & SD & Means & SD & \multirow{2}{*}{ Means } & SD \\
\hline Description & 16.43 & 3.98 & 19.66 & 3.13 & 18.54 & 3.76 \\
\hline Explanation & 16.07 & 3.24 & 18.51 & 3.53 & 17.67 & 3.61 \\
\hline Prediction & 13.50 & 4.05 & 16.17 & 3.02 & 15.25 & 3.62 \\
\hline Control & 21.54 & 3.04 & 23.26 & 1.58 & 22.67 & 2.33 \\
\hline
\end{tabular}

* The highest score for every goal is (24)

Table (7) shows that there is an apparent difference between the means of the participants' responses on every main objective of science attributed to the variable (possessing constructive characteristics). And to determine the statistical significance of these apparent differences, the multivariate one-way analysis of variance test MANOVA was implemented, see table (8).

Table 8. The One Way MANOVA of the means of the participants' responses of the science main objectives due to the variable (possessing constructive characteristics)

\begin{tabular}{|c|c|c|c|c|c|c|}
\hline Variable & Science main objectives & SS & $\mathrm{DF}$ & MS & F-value & Sig \\
\hline \multirow{4}{*}{$\begin{array}{c}\text { Possessing constructive characteristics } \\
\text { Hotelling's Trace }=0.381 \\
\text { *Statistical significance }=0.000\end{array}$} & Description & 191.355 & 1 & 191.355 & $* 16.138$ & 0.000 \\
\hline & Explanation & 108.898 & 1 & 108.898 & $* 9.220$ & 0.003 \\
\hline & Prediction & 130.590 & 1 & 130.590 & $* 11.257$ & 0.001 \\
\hline & Control & 54.734 & 1 & 54.734 & $* 11.401$ & 0.001 \\
\hline \multirow{4}{*}{ Error } & Description & 936.744 & 79 & 11.858 & & \\
\hline & Explanation & 933.102 & 79 & 11.811 & & \\
\hline & Prediction & 916.472 & 79 & 11.601 & & \\
\hline & Control & 379.266 & 79 & 4.801 & & \\
\hline \multirow{4}{*}{ Total } & Description & 1128.099 & 80 & & & \\
\hline & Explanation & 1042.000 & 80 & & & \\
\hline & Prediction & 1047.062 & 80 & & & \\
\hline & Control & 434.000 & 80 & & & \\
\hline
\end{tabular}

* The statistical significance difference at the level $(\alpha=0.05)$ 
Table (8) shows that the statistical significance value of the (Hotelling's Trace) test according to the variable (possessing constructive characteristics) is less than the statistical significance level at $(\alpha=0.05)$. This indicates that there is a statistical significance at least on one of the science main objectives (description, explanation, prediction, and control). And it is noted by looking at their values of the statistical significance that they are all less than the statistical significance level at $(\alpha=0.05)$, which indicates that there is a statistically significant difference between the two means of the participants' responses on every objective of the science main objectives that is attributed to the variable (possessing constructive characteristics). Based on the means in Table (7), the statistically significant difference is in the favor of the teachers who possess constructive characteristics.

\section{Discussion}

\subsection{Discussion of the First Question}

The result of this question indicates that female science teachers, in general, possess the characteristics of constructive theory to a moderate degree. Unsurprisingly, $(65.4 \%)$ of them possess the characteristics of constructive theory, where (34.6\%) of them do not possess them. This result is considered field evidence reflecting the reality of the teaching environment that female science teachers' possession of the constructive theory characteristics has not reached a high level. The reason can be attributed to the deficiencies in the educational programs in universities, like the bachelor's in science does not include teaching behavioral courses concerning the constructive theory, educational curricula, and teaching methods. Also, it may be attributed to the deficiencies in the training programs offered by the Directorate of Education for teacher's in-service regarding the constructive teaching methods. Resulting in a lack of possession of constructive theory characteristics among female teachers at the required level leads to the failure of female science teachers to consider and stimulate previous students' knowledge before teaching a new course and to link it to new knowledge. In addition to the fact that female teachers did not consider thinking skills or the use of higher mental processes, such as problem-solving, experimentation, exploring, and logical explanation to reach knowledge, and the lack of providing the opportunities for students to create and express their ideas, share them, use these ideas in different situations and focus on indoctrinating teaching among other principles of the constructive theory which teachers did not consider while teaching.

As suggested by Dawood and Al-Idwan [41], the constructive theory assumes that the interaction between the senses is not enough by itself to gain knowledge, but there is a necessity to work to benefit from the previous experiences possessed by the individual to generate new knowledge. As well, the principles of constructive teachers, as mentioned by Lew [29], are based on listening to students, allowing them to express their previous experiences about the subject being learned while providing feedback to the concepts the students have. Besides, the teachers' role does not include indoctrinating style only, but it extends to be a supervisor, guide, and facilitator of the learning process. In their turn, all these factors encourage students to be independent, lead and adopt more with the educational process which enhances the interaction levels between the student and the teacher.

Despite the educational content included in the constructive approach which emphasizes the quality of science learning, the actual reality reflects the absence of excellence in the learning environments. This result reflects the false concepts in the beliefs of female science teachers in the effective teaching performance in science learning, depending on the traditional approach of education which significantly focuses on receiving the knowledge, and the science teacher preoccupation with other variables, such as the pressure of finishing the whole curriculum, classroom management, and other routine work.

This result agrees with the study of Awad [36], which showed the degree of science teachers' knowledge of constructive theory and the degree their practicing teaching using this theory was moderate. At the same time, it differs from the results of Tura [38], which showed that the degree of practicing teaching based on constructive theory was high.

\subsection{Discussion of the Second Question}

The result of this question indicates that female teachers' mastery of all the main objectives of science is moderate, and the science objective (control) ranked first with a high degree, where the other objectives came with a moderate degree and in this order (description, explanation, prediction). Probably this result reflects a negative view of the female science teachers' mastery degree of the main science objectives and contradicts the global trends which emphasize the need to focus on science and its objectives as it is one of the important items of science education reform documents.

This result may be attributed to weakness and deficiencies in the training programs offered by the directorate of education to the teacher during their service (working) regarding the nature of science, or due to weakness and deficiencies in the programs offered by the universities for the degree of bachelor's in science which does not include courses about the nature of science. It may also be attributed to the structure and design of the educational content of the offered courses in the universities programs of science, which might not provide opportunities for students to investigate the reasons for the occurrence of a scientific phenomenon or events, or realize the relationships between the variables of these phenomenon and other related variables, or predict new 
future situations, or to use the general principles, laws, and theories to describe and explain the phenomenon and events. Or rather, implementing what was learned and employ it in new life situations led to the weakness of female teachers in the mastery of the science objectives.

This result may also be attributed to the diversity in the academic fields of female science teachers (chemistry, physics, biology, and earth science). Consequently, the science teacher who specializes in physics may not be familiar with the scientific phenomenon and events in the fields of chemistry, biology, or earth science. In other words, the teacher who is specialized in a specific academic major may not be familiar with the rest of the other scientific fields especially the scientific phenomenon and events. Thus, this may explain the moderate result of the female science teachers' mastery of the science main objectives. Even though the science teachers, as mentioned by Fernando and Marikar [28], should be academically qualified and possess the knowledge in the various topics intended to be presented to students. As well as they should benefit from the various educational methods to achieve active learning.

As for the science objective (control), which came in the first place with a high mastery, it may seem for the first moment that the result is illogical because the control goal is considered the implementation side of the main and most difficult science objectives. Accordingly, the four objectives (description, explanation, prediction, and control) have a hierarchical relationship that starts from the description, explanation, prediction and ends with control, which was the reason that opened the scientists' bath to discover the scientific phenomena and events. As for the result of this study, it can be attributed to the fact that the existing scientific phenomenon and events in the test that is prepared for this study are familiar to them and are included in the science textbooks which can be known easily as a result of the interaction of the senses with the outside world, such as avoiding the risk of an earthquake, reducing the manifestations of global warming or how to keep the shine of the silverware and prevent their surface from tuning into black among others. Contrarily, some phenomena cannot be controlled without describing them, interpreting them, or predicting them such as Aurora Borealis.

Regarding the science goal (prediction), this may be attributed to the weakness of the science teacher's mastery of the two previous objectives (description and explanation). Plus, the teachers' weak ability to use the information which resulted from them whether they are scientific principles, laws, or theories in predicting what might happen in the future. This weakness might reflect negatively on the teaching practices of the teacher; hence it might affect the interest in confirming the validity of the predictions. In addition to that, the reason behind the low percentage of prediction might be attributed to the focus of science curricula on the control skill and the two skills of description and explanation more than prediction. This result differs from Madi [32], which showed that the degree of teachers' mastery of the science main objectives was high.

\subsection{Discussion of the Third Question}

The result of this question indicates that there is no statistical significance difference between arithmetic averages of the study sample performance on the total test items, due to the educational qualification, years of experience, and the interaction between them.

Concerning educational qualification, this means that the teachers who have a bachelor degree only in science are not different from the teachers, who have an educational qualification that is higher than a bachelor degree, in their mastery degree of the science objectives and their ability to describe the phenomena, explain them, predict and control them, In other words, the educational qualification that is higher than a bachelor degree didn't contribute to raising the teachers' mastery degree of the science objectives.

This result may be attributed to the fact that the diploma and master's programs in education do not include courses related to describing scientific phenomena, explain, predict, or control them. Rather, the courses related to science nature refer to the science objectives in general, their meaning, and the importance of knowing them. Additionally, the nature of the phenomena and events in the science objectives test is at the level of school grades. Therefore, they might be realized by the teachers, despite the difference of their educational qualification, in the same way, because they teach these phenomena and describing, predicting, or controlling them predominantly scientific and that does not need an educational qualification. As well as the training programs offered by the directorate of education during service (work), targets all the male and female teachers regardless of their educational qualification, and which is often concentrated on the educational side that is related to teaching methods and evaluation. All of this may have resulted in not having a difference between the teachers in their mastery degree of the science objectives despite the difference in their educational qualification.

This result differs from the results of Madi [32], which showed that there are statistically significant differences between the means of the study sample performance in the favor of teachers with a higher educational qualification than a bachelor.

And about the result concerning "years of experience", it specifies that the female teacher repeats herself through her years of experience and that her experience didn't contribute to the teachers realization of the science main objectives and developing them, this may be due to a lack of training programs offered by the ministry of education for teachers in-service, which led to the fact that teachers with short experience don't differ from the teachers with long experience in mastering the science objectives. This result may also be attributed to the fact that teachers do 
not develop themselves during service, probably because of the teachers' heavy burden and responsibilities as housewives, or because of the educational curricula structure and the textbooks did not mention adequate information about some phenomenon or lack of educational resources and references to help strengthen the mastery of the objectives of science by female science teachers.

Regarding the correlation between the variable of the educational qualification and years of experience, the findings show no statistical significance. This result is logical as there is no statistical significance effect for both the teaching experience and the educational qualification in the female science teachers' performance on the overall scale. Therefore, it is normal not to have a common effect on the correlation between them. In other words, there is no difference between the female teachers with educational qualifications and the years of experience in their mastery level of science objectives.

\subsection{Discussion of the Fourth Question}

The result of this question indicates that there are statistically significant differences between the averages of the study sample performance on the overall test items of science objectives, and on every main objective attributed to the variable of (possessing constructive characteristics), and in favor of the teachers who possess constructive characteristics.

This result can be explained by the fact that the teacher who has enough knowledge about the constructive theory can reinforce the students learning by linking the new information with a specific phenomenon or event with the previously existing mental schema which the students have. This explanation is supported by Orey [30], who mentioned that the constructive teacher is the one who provides the different tangible supports and visual aids that help in implementing the educational activities. This makes it easy to learn the complicated concepts, provides the students with the opportunity to classify the information, reinforces the students' ability to analyze and predict which strengthens the relationships between the student and the teacher.

This result might also be attributed to the fact that the constructive teacher uses constructive teaching methods while teaching, especially the scientific phenomenon and events which need to upgrade the skills of description, explanation, prediction, and control to emphasize the science objectives. On the one hand, the description objective requires the teacher to reinforce the accuracy of observation, either by invoking the previous knowledge around a phenomenon by asking some questions about what they have observed and provide the opportunity by explaining and expressing their ideas or to ask the students to describe phenomenon and events. On the other hand, the explanation skill requires presenting situations and experiences which generate cognitive contradictions among students. This encourages the students to develop hypotheses and test them. As for the prediction process, it is to summon the previous information which resulted from the description and explanation skills to predict some unknown information to students, as well as the mental deducing and the practical experimentation to confirm their validity. However, the control skill needs to apply what has been learned and correct it. And this is the teaching behavior that characterizes the constructive teacher in general which might make the constructive teacher mastery the science objectives more than the traditional teacher.

\section{Conclusions}

The study results showed that the mastery level of female science teachers of the science objectives was moderate, and their level in possessing the constructive theory characteristics from their students' point of view was moderate. It also pointed out that the female teachers, who possessed the constructive theory characteristics, mastered the science goals more than the female teachers who did not possess the constructive theory characteristics. This stressed the importance of teachers understanding and practicing the constructive theory principles and assumptions to understand the science objectives and master them, because this may have a positive impact on their teaching practices with students, as understanding the science objectives was considered one of the most important objectives of teaching science that was based on describing, explaining, predicting, and controlling the phenomena. From this, the study recommended the necessity to develop programs to train the teachers by providing courses about the nature of science and including the constructive theory principles as its advantages can contribute to the development of teaching science. On the other hand, the way, and the accurate explanation of the constructive theory's role in understanding and mastery of the science objectives may require further research and analysis to understand the correlation between them.

\section{Recommendations}

In the light of the study results, the researchers recommended the following:

- Increase the awareness of the science main objectives and hold training courses for the science teachers that aim to develop their philosophical perspectives about science, before and during service.

- Adopt mandatory studies and courses in the university which reinforce the science teachers' mastery of the science main objectives.

- Conduct more studies related to the science main objectives and on different samples and link them with other variables such as the teacher's educational behavior, or the course that deals with the science main objectives, gender, or in-service training courses. 


\section{Acknowledgments}

The study was funded by a grant from the Deanship of Research at Yarmouk University.

\section{Appendices}

Appendix (1). The Constructive theory characteristics scale

\begin{tabular}{|c|c|c|c|c|c|c|}
\hline & & & & Degree & & \\
\hline $\mathrm{N}$ & Item & $\begin{array}{l}\text { Very } \\
\text { high }\end{array}$ & High & Moderate & Low & $\begin{array}{l}\text { Very } \\
\text { low }\end{array}$ \\
\hline 1 & The teacher encourages the student's initiatives. & & & & & \\
\hline 2 & $\begin{array}{l}\text { The teacher uses concepts and verbs, such as: (describe, analyze, predict, and design), while } \\
\text { preparing the tasks and activities which the students well implement. }\end{array}$ & & & & & \\
\hline 3 & The teacher encourages us to have a talk or discussion during the class. & & & & & \\
\hline 4 & $\begin{array}{l}\text { The teacher encourages us to investigate by asking open-ended and thought-provoking } \\
\text { questions. }\end{array}$ & & & & & \\
\hline 5 & $\begin{array}{l}\text { The teacher presents situations and experiences that generate cognitive contradictions for the } \\
\text { students. }\end{array}$ & & & & & \\
\hline 6 & The teacher gives us enough time to think of an answer after asking the question. & & & & & \\
\hline 7 & $\begin{array}{l}\text { The teacher pays great attention to the method used to reach the knowledge and not } \\
\text { memorizing knowledge itself. }\end{array}$ & & & & & \\
\hline 8 & The teacher pushes us to participate actively to take responsibility for our learning. & & & & & \\
\hline 9 & The teacher encourages the students to learn by developing and testing the hypothesis. & & & & & \\
\hline 10 & $\begin{array}{l}\text { The teacher encourages us to have a different alternative to solve life's problems and not to } \\
\text { be satisfied with just one answer. }\end{array}$ & & & & & \\
\hline 11 & The teacher involves us in defining the things we want to learn. & & & & & \\
\hline 12 & $\begin{array}{l}\text { The teacher involves us in evaluating learning and the information we obtained and moving } \\
\text { towards the objectives. }\end{array}$ & & & & & \\
\hline 13 & $\begin{array}{l}\text { The teacher seeks to help the students to work efficiently with others by cooperation and } \\
\text { teamwork. }\end{array}$ & & & & & \\
\hline 14 & The teacher avoids giving direct answers. & & & & & \\
\hline 15 & The teacher seeks to have the student's ideas and suggestions. & & & & & \\
\hline 16 & The teacher repeats the study plan when it is updated. & & & & & \\
\hline 17 & $\begin{array}{l}\text { The teacher considers the learning depends on the student, while the teacher role is limited to } \\
\text { facilitating learning. }\end{array}$ & & & & & \\
\hline 18 & The teacher encourages us to do activities about what we learn. & & & & & \\
\hline 19 & $\begin{array}{l}\text { The teacher accustoms the students to benefit from the learned concepts and mental } \\
\text { processes in new situations. }\end{array}$ & & & & & \\
\hline 20 & $\begin{array}{l}\text { The teacher encourages us to learn from different sources and not limit ourselves to school as } \\
\text { a place of learning. }\end{array}$ & & & & & \\
\hline 21 & The teacher uses the educational resources and techniques. & & & & & \\
\hline 22 & $\begin{array}{l}\text { The teacher presents scientific problems to the students which involve a challenge that is } \\
\text { appropriate for their thinking and can be solved. }\end{array}$ & & & & & \\
\hline 23 & The teacher presents the material in different ways. & & & & & \\
\hline 24 & The teacher avoids the methods of direct transmission of information to the students' minds. & & & & & \\
\hline 25 & The teacher follows-up with the students while finishing the required tasks in the activity. & & & & & \\
\hline 26 & The teacher encourages us to build knowledge through group discussions. & & & & & \\
\hline 27 & The teacher accepts the students' mistakes as a resource for their learning. & & & & & \\
\hline 28 & The teacher encourages us to criticize the presented ideas and concepts. & & & & & \\
\hline 29 & The teacher allows us to talk about what we know (knowledge store). & & & & & \\
\hline 30 & The teacher directs us to multiple and modern educational resources. & & & & & \\
\hline 31 & The teacher puts us into groups in a way that achieves interactive participation. & & & & & \\
\hline 32 & The teacher employs our ideas, experiences, and interests to improve our learning. & & & & & \\
\hline 33 & The teacher presents our achievements in the classroom or inside the school. & & & & & \\
\hline 34 & The teacher allows us to ask questions and present our ideas. & & & & & \\
\hline 35 & The teacher involves us in planning what will be learned. & & & & & \\
\hline 36 & The teacher encourages us to explain our learning results to the rest of the class. & & & & & \\
\hline 37 & The teacher gives the students enough time to talk and discuss the learning process. & & & & & \\
\hline 38 & The teacher provides the students with feedback and corrects their misconceptions. & & & & & \\
\hline 39 & The teacher considers our previous knowledge before teaching begins. & & & & & \\
\hline 40 & The teacher allows us to link between the previous and the new knowledge. & & & & & \\
\hline 41 & The teacher avoids answering the students' questions with other questions. & & & & & \\
\hline 42 & The teacher involves us to participate in the evaluation process of our performance. & & & & & \\
\hline
\end{tabular}




\section{Appendix (2)}

Science main objectives test

One: the occurrence of iron rust phenomena.

a. Describe iron rust phenomena?

b. Explain the cause of iron rust?

c. What do you expect to happen for the iron in the dry air?

d. How can these phenomena be prevented from happening?

Two: the phenomena of color changing of the silverware into black.

a. Describe the phenomena of color changing of the silverware into black?

b. Explain the cause of this phenomenon?

c. what do you expect to happen for the silver filling of the teeth with time?

d. How can the shine of the silverware be kept and prevent the surface from turning black?

Three: tooth decay phenomena.

a. Describe tooth decay?

b. Explain why tooth decay happens?

c. What happens to the teeth if the mouth become dry?

d. How can we protect our teeth from decay?

Four: Acid rain phenomena.

a. Describe acid rain?

b. Explain why acid rain occurs?

c. What is the effect of acid rain on humans?

d. How can the acid rain effect be reduced?

Five: Global warming phenomena.

a. Describe global warming phenomena?

b. Explain why global warming occurs?

c. What are the most important natural phenomena

which lead to global warming?

d. How can global warming manifestation be reduced?

Six: Wind phenomena.

a. Describe wind phenomena?

b. Explain why this phenomenon occurs?

c. What do you expect to happen for the wind speed as we go higher than the sea level?

d. How this phenomenon can be controlled in favor and service of the main kind?

Seven: Earthquakes phenomena.

a. Describe the earthquake phenomena?

b. Explain why earthquakes occur?

c. What do you expect to happen for the buildings of the earthquake strength was (6) on the Mercalli scale? d. How can we prevent earthquakes from happening?

Eight: the alternation of day and night.

a. Describe the alternation of day and night?

b. Explain why the alternation of day and night occurs?

c. What do you expect to happen if the earth does not revolve around itself while it revolves around the sun? d. What are the benefits of this phenomenon for living things?

Nine: moon phases

a. Describe the moon phases which we see in the sky during the month?

b. Explain why the moon phases which we see in the sky during the month occur?

c. What do you expect to happen if the moon stopped revolving with the earth around the sun?

d. What are the benefits of learning about these phases?

Ten: human genetic traits

a. Describe human genetic traits.

b. Explain how genetic traits occur for humans.

c. What do you expect to happen to the children's hair type if one of their parents has pure curly hair?

d. How transmit genetic diseases can be reduced?

Eleven: bread mold phenomena

a. Describe bread mold phenomena.

b. Explain why this phenomenon occurs.

c. What do you expect to happen if we put the moldy bread in the refrigerator?

d. How this phenomenon can be prevented, and how can we benefit from it?

Twelve: living things environmental adaptation.

a. Describe environmental adaptation?

b. Explain why living things can adapt to their environment?

c. What is the method used by scientists in studying and learning about living things adaptation through millions of years?

d. How can humans provide a safe environment for endangered animals?

\section{REFERENCES}

[1] Zaiton, H., \& Zaiton, K. Learning, and teaching in the light of constructive theory, $1^{\text {st }}$ ed, Cairo: Alam Al-Kotob, 2003.

[2] Kaufman, D.Constructivist issues in language learning and teaching, Annual review of applied linguistics, no. 24, pp. 303-319, 2004.

[3] Lee, M. What does constructivism suggest for science education? California State University, Northridge, California, 2006.

[4] Jones, M., \& Brader-Araje, L. The impact of constructivism on education: Language, discourse, and meaning, American Communication Journal, vol. 5, no.3, pp. 1-10, 2002.

[5] Zaiton, A. The constructive theory and science teaching strategies, Amman: Dar Alshorok publishing \& distribution, 2007.

[6] Zaiton, A."The level of understanding the nature of 
scientific endeavor in the light of project (2061) among science teachers in Jordan and its relationship to some demographic variables", The Jordanian Journal of Educational Sciences, vol. 9, no. 2, pp. 139-119, 2013.

[7] Abdel Halim. The nature of science is an applied Islamic vision in science education, $1^{\text {st }}$ ed, Cairo: The world of books, 2002.

[8] De Boer, G. Scientific literacy: Another look at its historical and contemporary meanings and its relationship to science education reform, Journal of Research in Science Teaching: The Official Journal of the National Association for Research in Science Teaching, vol. 37, no. 6, pp.582-601, 2000

[9] Kitch, M.The Philosophy of training the teacher in the light of the contemporary challenges, $1^{\text {st }}$ ed, Cairo: Elkitab Publishing Center, 2001

[10] Bhattacherjee, A.. Social science research: Principles, methods, and practices, $2^{\text {nd }}$ ed., Creative Commons attribution non-commercial- share-alike 3.0 Unported License, 2012.

[11] Al-Najdi, A., Rashid, A., \& Abdul-Hadi, M. Introduction to teaching science, Cairo: Dar Elfikr Elarabi, 1999.

[12] American Association for the Advancement of Science [AAAS], Science for all American: a project (2061) report on literacy goals in science, mathematics, and technology, Washington DC,1989.

[13] Bolisani, E., \& Bratianu, C. The elusive definition of knowledge in emergent knowledge strategies, Cham: springer international publishing, 2018.

[14] Al-Qudah, M. The level of understanding the science nature according to (NSTA) standards of science teachers in Jordan in the light of some variables, Unpublished master thesis, Al-Albayt University, Jordan, 2016.

[15] Duadri, R. The scientific research: its theoretical basics and its scientific practices, $1^{\text {st }}$ ed, Damascus: Dar Al-fikr, 2000.

[16] Aydeniz, M., \& Ozdilek, Z. Assessing pre-service science teachers' understanding of scientific argumentation: What do they know about argumentation after four years of college science?", Science Education International, vol. 26, no. 2, pp. 217-239, 2015.

[17] Zaiton, A., The nature and structure of science: Its applications in the practical education, $1^{\text {st }}$ ed, Amman: Dar Ammar publishing \& distribution, 1991.

[18] Beins, B., \& McCarthy, M. Research methods and statistics, USA: Pearson Education, Inc, 2012.

[19] Al-Azaui, R. An introduction to the scientific research method, Amman: Dar Dejlah, 2008.

[20] Mubarak, M. Scientific research: Its basics and way of writing, Cairo: Al-Ahram publishing \& distribution agency, 1992.

[21] Al-Hajri, H. The level of science teachers' understanding of science nature and its relationship to classroom practices, Unpublished M.A thesis, Sultan Qaboos University, Oman, 2006.

[22] Al-Mshhadani, S. Research methodology, Lebanon \&
United Arab Emarites: University Book House, 2017.

[23] Musleh, A., \& Nada, Y. Scientific research in Al-Quds Open University: Motivations and obstacles from full-time academic supervisors' viewpoint", Journal of Al-Quds Open University for Research and Studies, no. 9, pp. 157-197, 2007.

[24] Gijbels, D., \& Loyens, S. Constructivist learning (environments) and how to avoid another tower of Babel: reply to Renkl", Instructional Science, vol. 37, no.5, pp. 499-502, 2009.

[25] Atia, M. The Constructive Theory, and its Applications: Modern Teaching Strategies, $1^{\text {st }}$ ed. Amman: Dar Al-Manhajiah Publishing \& Distribution, 2015.

[26] Suhendi, A., \& Purwarno, P. Constructivist learning theory: The contribution to foreign language learning and teaching", KnE Social Sciences, vol. 3, no. 4, pp. 87-95, 2018.

[27] Juvova, A., Chudy, S., Neumeister, P., Plischke, J., \& Kvintova, J.Reflection of constructivist theories in current educational practice", Universal Journal of Educational Research, vol. 3, no. 5, pp. 345-349, 2015.

[28] Fernando, S., \& Marikar, F. Constructivist teaching/learning theory and participatory teaching methods, Journal of Curriculum and Teaching, vol. 6, no. 1, pp. 110-122, 2017.

[29] Lew, L. The use of constructivist teaching practices by four new secondary school science teachers: A comparison of new teachers and experienced constructivist teachers, Science Educator, vol. 19, no. 2, pp. 10-21, 2010.

[30] Orey, M. Emerging perspectives on learning, teaching, and technology, North Charleston: CreateSpace, 2010.

[31] Al-Mousi, A. The Arabic language teachers in the standards of their scientific, professional, and cultural preparation, $1^{\text {st }}$ ed, Amman: Redwan publishing house, 2015.

[32] Madi, F. The level of science teachers understanding of science nature and philosophy in the light of some variables, Unpublished M.A thesis, Al-Quds University, Palestine, 2010.

[33] Gray, A. Constructivist teaching and learning, Unpublished master's thesis, University of Saskatchewan, Canada, 1997.

[34] Barakat, M. The employment degree of constructive theory by science male and female teachers in Jordan, Unpublished M.A thesis, Jordanian University, Jordan, 2002.

[35] Shumba, A.Teachers' conceptions of the constructivist model of science teaching and student learning, The Anthropologist, vol. 13, no. 3, pp. 175-183, 2011.

[36] Awad, A., The degree of science teachers' knowledge of constructive theory and the degree of their teaching practices based on it, and their impact on the students' achievement, Unpublished M.A thesis, The Hashemite University, Jordan, 2005.

[37] Habib, R. The reality of using the constructive teaching practices among the primary education teachers in Gaza province, Unpublished M.A thesis, Al-Azhar University, Palestine, 2015. 
[38] Al-Tura, M. The level of science teacher's application of constructive theory in Ma'an province, Unpublished M.A thesis, Al-Hussein University, Jordan, 2017.

[39] Aslan, O., \& Tasar, M. How do science teachers view and teach the nature of science? A classroom investigation, Education \& Science/ Egitim ve Bilim, vol. 38, no. 167, pp. 65-80, 2013.
[40] Odeh, A. Measurement, and evaluation in the teaching process, Jordan: Dar Al-Amal publishing \& distribution, 2014.

[41] Dawood, A., \& Al- Idwan, Z. The constructive social theory, and its implications to teaching. Amman: Debono center for teaching thinking, 2016. 